\title{
Agarwood-type Resin from Gyrinops walla Gaertn: A New Discovery
}

\author{
S.M.C.U.P. Subasinghe* ${ }^{1}$, D.S. Hettiarachchi ${ }^{2}$, E. Rathnamalala ${ }^{3}$ \\ ${ }^{1}$ Department of Forestry and Environmental Sciences, University of Sri Jayewardenepura \\ ${ }^{2}$ Wescorp Agarwood, Wescorp Group, Canning Vale, Western Australia, Australia \\ ${ }^{3}$ Sadaharitha Plantations Limited, Alfred Place, Colombo 03, Sri Lanka
}

Date Received: 29-03-2012 Date Accepted: 21-06-2012

\begin{abstract}
Agarwood is an expensive resinous product extracted from some members of Aquilaria and Gyrinops species of the family Thymalaeaceae. Agarwood essential oil is a highly valued perfumery product in modern cosmetics and traditional Attar. Agarwood extraction from the above species and product manufacturing are done in India and Southeast Asian countries. However, overharvesting, low natural regeneration, and legal restrictions at present, have limited the supply of this product.

Gyrinops walla is recorded in the wet zone of Sri Lanka, and it had been very rarely recorded in extreme Southwest India. However, recent reports of the abundance of G. walla in India are hard to find. Studies were not conducted in the past for $G$. walla on its ability of agarwood resin production and the quality of that resin. This study is the first to identify the agarwood resin formation and the quality of $G$. walla which can be used as a substitute for that of Aquilaria and other species of Gyrinops.

Resinous tissues were extracted from six G. walla trees for the present study from two different areas, i.e., Labugama and Yagirala of the wet zone of Sri Lanka. The resins were solvent extracted in the laboratory and the resin quality was tested using gas chromatography analysis. The results indicated an extreme similarity of the compounds of $G$. walla resin with that of commercially available agarwood resins. However, further studies should be conducted to identify $G$. walla distribution and formation of agarwood.
\end{abstract}

Key words: Gyrinops walla, Aquilaria, agarwood

\section{Introduction}

Internationally, agarwood is widely known for its fragrant resinous wood. Agarwood refers to species within four genera: Gyrinops, Aetoxylon, Gongystylis and more commonly, Aquilaria within the family Thymalaeaceae. The value of the resin currently found in a small percentage of trees mainly harvested from certain species in the genus Aquilaria. The process of the oleo-resin production is the tree's response to injury of its first line of defence, formation of phloem callus tissue, is inhibited from forming over the injury (Blanchette, 2003). The resin derived from the agarwood tree is highly sought after for religious, medical, ceremonial and domestic activities by Asian Buddhists and Moslems. In addition to that, a large demand is seen for agarwood in Southeast Asia, Middle East and United States as a perfumery agent.

*Correspondence: upuls@sjp.ac.lk

Tel: +94-112758421, Fax: +94 112803470

ISSN 2235-9370 Print / ISSN 2235-9362 Online (C2012 University of Sri Jayewardenepura 
Certain species of Aquilaria and Gyrinops, the two important agar producing genera are normally distributed in at least 12 countries: Bangladesh, Bhutan, Cambodia, India, Indonesia, Lao PDR, Malaysia, Myanmar, Philippines, Thailand, Vietnam and Papua New Guinea (Stevens, et al., 2003). However, G. walla has not been included into the agarwood producing species.

Aquilaria trees are native to Asia from northern India to Vietnam and Indonesia (Blanchette et al., 2005). However, none of the species of the Aquilaria genus has been recorded in Sri Lanka. G. walla is the only member in Sri Lanka of the genus Gyrinops. According to Dassanayake and Fosberg, (1981), outside the wet zone of Sri Lanka, G. walla had been recorded only in the extreme southwest of India, where it appeared to be very rare. Therefore it can be assumed that, G. walla occurs only in Sri Lanka at present based on the lack of information on finding this species in India.

G. walla is a medium tall tree which grows up to $15 \mathrm{~m}$ in height with straight, slender trunk with a small, rounded crown. The bark of this species is brownish-grey and it is thin, smooth and strongly fibrous. Therefore its bark is used as a binding material by the villagers. Twigs are slender and wiry, rather shining and chestnut-brown in colour when young. Leaves are oblong and 3.0-9.0 cm x 1.2-5.0 cm with a short, rather abrupt, bluntish acumen up to $1 \mathrm{~cm}$ long. Petiole is short and 1-6 mm in length. Inflorescence is terminal or few flowered with umbel-like heads. Pedicels are 3-4 $\mathrm{mm}$ and thinly pilose. Flowers are yellowish-white and the size of the calyx tube is $4-10 \mathrm{~mm}$ which is narrow (Dassanayake and Fosberg, 1981).

Papua New Guinea uses Gyrinops, locally known as eaglewood instead of Aquilaria as agarwood. Eaglewood was first discovered and harvested for resin production in Papua New Guinea in about 1998. At that stage, information on the species was unknown. It was only in 2001 that taxonomic work was undertaken which determined the species as Gyrinops ledermannii. This was the first official recording of this species being harvested for their resin wood.

Fragrant compounds of agarwood are known to be sesquiterpenoids and chromone derivatives, which are the main source of agarwood's particular odour (Takemoto et al., 2008). Agarwood oils vary in their composition; some oils contain a large amount of sesquiterpene compounds and others contain principally benzylacetone (Yang et al., 1989). In addition to that, Okugawa et al. (2000) reported that six sesquiterpenoids, namely jinkoh-eremol, agarospirol, alpha and beta santalols, dehydrocostus lactone and costunolide, isolated from agarwood, inhibited acid-induced writhing in mice (Takemoto et al., 2008).

\section{Methodology}

The objective of the present study was to identify the resin production ability of G. walla trees and to match the resin quality with that of commercially available authentic samples extracted from Aquilaria species.

\subsection{Sampling}

Six trees growing in two distinctive areas of the wet zone of Sri Lanka, i.e., Labugama, of Seethawaka DS Division, Colombo District and Yagirala of Walallawita DS Division, Kalutara District were used for the present study (Table 1).

\subsection{Resin extraction}

The sample collection was done in November-December period of 2011. Due to the unavailability of the records, the ages of the trees were not known. All six trees mentioned in table 1 had been naturally wounded sometime before the sample collection due to abrasions or wind-fallen branches. Those areas were carefully observed and the decaying, black colour tissues were extracted using a pruning saw and a chisel. Those samples were size reduced using a sharp edge cutter at the laboratory. Those samples were air-dried and then put in a glass vial and the resin extraction was done using di-chloro methane. This 
process was repeated up to three times. Combined extract was then evaporated under negative pressure and sample was stored away from light until further analysis.

Table 1: Location details and sizes of the six trees used for the study

\begin{tabular}{lrrrrr}
\hline Location & Tree no. & Dbh $(\mathrm{cm})$ & Height $(\mathrm{m})$ & Latitude & Longitude \\
\hline Labugama & 01 & 12.0 & 8.0 & $6^{0} 48^{\prime} 58.496^{\prime \prime}$ & $80^{0} 10^{\prime} 25.352^{\prime \prime}$ \\
& 02 & 21.5 & 12.0 & $6^{0} 48^{\prime} 28.699^{\prime \prime}$ & $80^{0} 10^{\prime} 24.917^{\prime \prime}$ \\
Yagirala & 03 & 30.0 & 20.0 & $6^{0} 48^{\prime} 26.161^{\prime \prime}$ & $80^{0} 10^{\prime} 26.612^{\prime \prime}$ \\
& 04 & 22.5 & 10.5 & $6^{0} 21^{\prime} 40.064^{\prime \prime}$ & $80^{0} 10^{\prime} 41.732^{\prime \prime}$ \\
& 05 & 15.0 & 7.5 & $6^{0} 21^{\prime} 39.967^{\prime \prime}$ & $80^{0} 10^{\prime} 41.830^{\prime \prime}$ \\
& 06 & 8.5 & 8.0 & $6^{0} 21^{\prime} 40.259^{\prime \prime}$ & $80^{0} 10^{\prime} 42.708^{\prime \prime}$ \\
\hline
\end{tabular}

\subsection{Gas chromatography analysis}

Weighed amount of the extract was dissolved in ethyl acetate to make a $10 \mathrm{mg} \mathrm{ml}^{-1}$ solution. This solution was then injected $(1 \mu \mathrm{l})$ to the gas chromatography instrument (GC2010, Shimadzu Scientific, Japan) using an auto sampler (AOC20i, Shimadzu Scientific, Japan). Separation was performed using a $5 \%$ phenyl-polysiloxane coated $30 \mathrm{~m} \times 0.25 \mathrm{~mm} \times 0.25 \mu \mathrm{m}$ column (AT-5, Alltech, USA). Injector chamber was kept at $250^{\circ} \mathrm{C}$, whereas oven was programmed to increase from $120-250^{\circ} \mathrm{C}$ at the rate of $5^{0}$ $\mathrm{Cmin}^{-1}$ and held for 5 minutes. Flame ionisation detector was held at $300^{0} \mathrm{C}$. Data were processed using the Lab Solutions software (Shimadzu Scientific, Japan). Standard alkane series of C8 to C40 (SigmaAldrich, USA) was used for the determination of retention indices. Calibration curve was used to calculate the Kovat's retention indices. Chromatograms and indices obtained from authentic agarwood samples were used for confirmation of published data.

\section{Results}

Although, G. walla is a medium height tree which reaches up to $15 \mathrm{~m}$ (Dassanayake and Fosberg, 1981), the tree number 03 which was a free-grown tree at the edge of a homegarden of Labugama has reached $20 \mathrm{~m}$ in height (Table 1) at the time of sample collection. The heights of all other five trees were comparatively smaller.

The resin contents of the samples varied from $4.4 \%$ to $10.9 \%$ with an average of $6.81 \%$. However, since artificial resin induction had not been done and the naturally wounded areas of the selected trees were used for the present study, the pattern of the development of the tissues of the plants was not identified.

The gas chromatography analysis revealed that the resin of $G$. walla found to contain several aroma principles commonly found in agarwood (Table 2). All types of agarwood found to contain oxoagarospirol and jinkoh-eremol (Yoneda et al., 1984). Even though the presence of these compounds was lower in the analysed $G$. walla samples of the current study, they are important markers in identifying agarwood aroma (Figure 1). Sesquiterpenes of guaiane and eudesmane skeleton were also present in $G$. walla resin. These compounds were known to produce characteristic camphor like aroma with woody and floral notes (Ishihara et al., 1991). Apart from this, many fatty acids were also found to be common between the authentic and test samples. However, these resins were found to lack agarofuran, vetivae sequiterpenes and chromone derivatives, which are key components of the resin formed in Aquilaria species (Naf et al., 1993). 
Table 2: Retention indices and the percentage areas of test and authentic samples

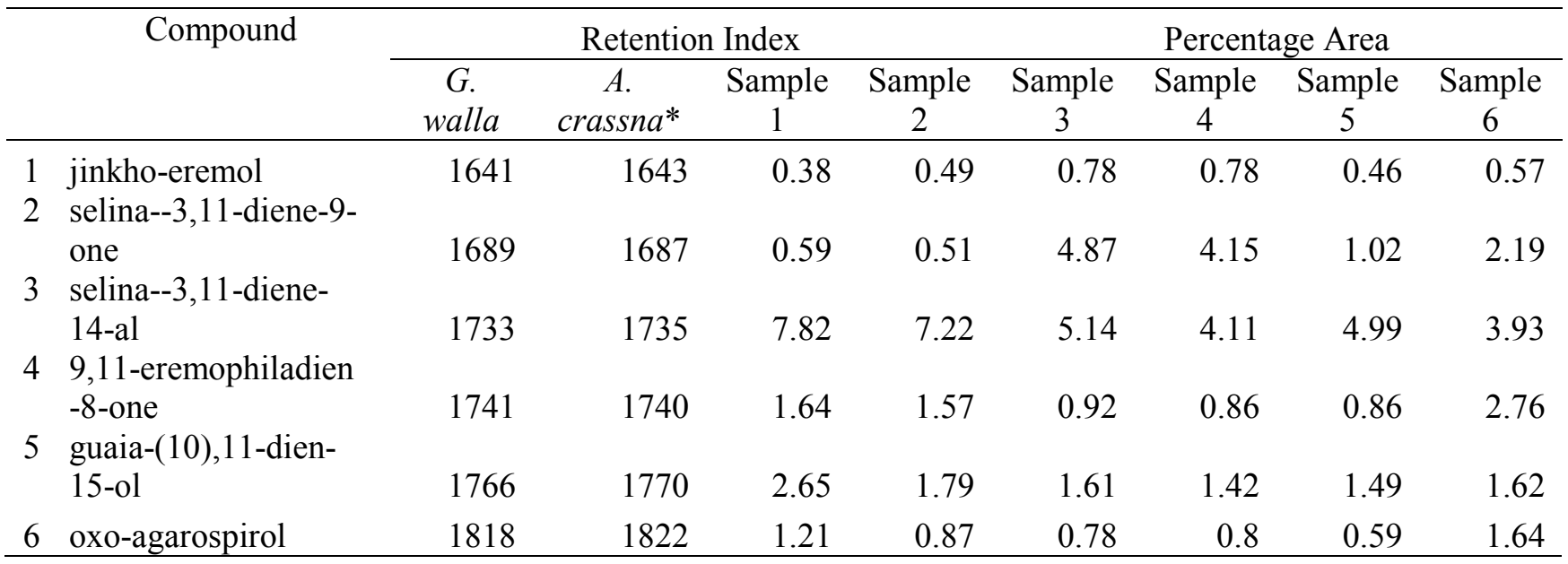

* Source: Wetwitayaklung et al. (2009)

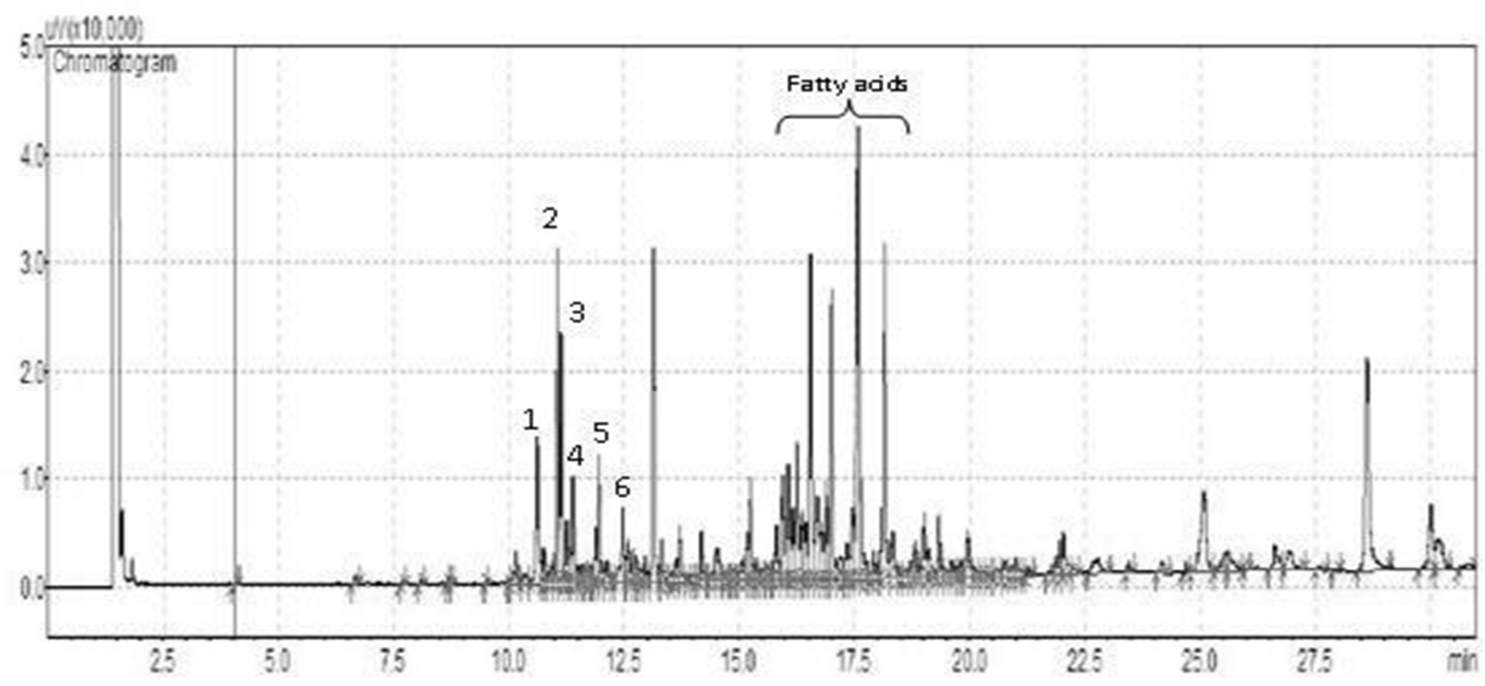

Figure 1: Chromatogram of the test sample 06.

\section{Discussion and conclusions}

The genera Aquilaria and Gyrinops are well known for the production of agarwood which is highly wanted for forest product of substantial economic value (Eurlings and Gravendeel, 2005). According to $\mathrm{Ng}$ et al. (1997), out of 15 recorded species, nine species of Aquilaria, i.e., A. beccariana, A. crassna, A. filaria, A. hirta, A. khasiana, A. malaccensis, A. microcarpa, A. rostrata, and A. sinensis produce agarwood. In addition, agarwood production has been recorded from Gyrinops ledermanii and $G$. versteegii (Compton and Zich, 2002) although there are eight recorded species in the genus Gyrinops. However, this is the first time of identifying the ability of $G$. walla for producing agarwood. However, more studies are required in this aspect to identify the potential of harvesting the resins from $G$. walla at commercial scale.

A study conducted on agarwood oil by Takemoto et al. in 2008 proved that the constituents of agarwood oil vary between trees. In their study they found that the agarwood oil tested in one sample had benzylacetone $(47.1 \%)$ as the main volatile compound while alpha-aurjunene $(62.5 \%)$ was the main compound of the second oil sample. 
Current method of gas chromatographic analysis could be used in identifying agarwood aroma principles from the trees of Thymelaeaceae family. All six samples tested in the present study, have shown similar compounds according the gas chromatographic trace (fingerprint). Majority of these compounds were unidentified due to the lack of references. In future, however, a gas chromatograph coupled with a mass spectrometer will be used to identify the remaining compounds.

Difference in the extraction method could play a significant role in the chemical properties of the resin rather than the biological origin. Samples discussed in this study were extracted using a nonexhaustive solvent extraction method in comparison to a long hydro-distillation used in commercial agarwood production. In future, a sufficient sample will be collected and be subject to hydro-distillation to compare with an authentic agarwood oil samples.

Based on the results of the present study, it can be concluded that the current findings give a promising result for the first time on the resin formed in Gyrinops walla and its capacity to produce agarwood type resins.

\section{References}

Blanchette, R.A. 2003. Deterioration in historic and archaeological woods from terrestrial sites. In Koestler, R.J., Koestler, V.R., Charola, A.E., and Nieto-Fernandez, F.E. (Eds), Art, biology and conservation: Biodeterioration of works of Art. The metropolitan Museum of Art, New York, 328$347 \mathrm{pp}$.

Blanchette, R.A. and van Beek, H.H. 2005. Cultivated agarwood: Patent No. 6,848,211 B2. United Estate Patent

Compton, J.G.S. and Zich, F.A. 2002. Gyrinops ledermannii (Thymalaeaceae), being an agarwood producing species prompts call for further examination of taxonomic implications in the generic delimitation between Aquilaria and Gyrinops. Flora Malesiana bulletin 13(1): 61-66

Dassanayake, M.D. and Fosberg, F.R. 1981 Flora of Sri Lanka: Vol II. 1981. Oxford and IBH Publishing Company, New Delhi

Eurlings, M.C.M. and Gravendeel, B. 2005. TrnL-TrnF sequence data imply paraphyly of Aquilaria and Gyrinops (Thymalaeaceae) and provide new perspectives for agarwood identification. Plant Systematics and Evolution 254: 1-12

Gunn, B., Stevens, P., Singadan, M., Sunari, L. and Chatterton, P. 2003. Eglewood in Papua New Guinea. RMAP working paper no 51

Ishihara, M., Tsuneya, T., Shiga, M. and Uneyama, K., 1991. Three sesquiterpenes from agarwood. Phytochemistry 30(2): 563-566\

Naf, R., Velluz, Thommen, W., Brauchli, R., Sigwart, C. and Gaudin, J-M., 1993. New Compounds Identified in Agarwood (Aquillaria aggalocha Roxb.) Flavour and Fragrance Journal, 8: 307-313

Ng, L.T., Chang, Y.S. and Kadir, A.A. (1997). A review on agar (gaharu) producing Aquilaria species. Journal of Tropical Forest Products 2 (2): 272-285.

Okugawa, H., Ueda, R., Matsumoto, K., Kawanishi, K. And Kato, K. (2000). Effects of sesquiterpenoids from "Oriental incenses" on acetic acid-induced writhing and D2 and 5-HT2A receptors in rat brain. Phytomedicine 7(5): 417-422.

Takemoto, H., Ito, M., Shiraki, T., Yagura, T. and Honda, G. 2008. Sedative effects of vapour inhalation of agarwood oil and spikenard extract and identification of their active components. Journal of Natural Medicine 62: 41-46.

Wetwitayaklung, P., Thavanapong, N. and Charoenteeraboon, J., 2009. Chemical Constituents and Antimicrobial Activity of Essential oil and Extracts of Heartwood of Aquilaria crassna Obtained from Water Distillation and Supercritical fluid Carbon Dioxide Extraction. Silpakorn University of Science and Technology Journal. 3 (1): 25-33. 
Yang, J.S., Wanf, Y.L., Su, Y.L., He, D.H., Zheng, Q.T. and Yang, J. 1989. Studies on the chemical constituents of Aquilaria sinensis (Luor) Gilg. III. Elucidation of the structure of the isobaimuxinol and isolation and identification of the constituents of lower boiling fraction of the volatile oil. Yao Xue Xue Bao 24(4): 264-268.

Yoneda, K., Yamagata, Etsuko, E., Tsutomu, N., Tsukasa, N, Ichiro, K., Toshio, Y, Hideo, M. and Iwao, M. 1984. Sesquiterpenoids in two different kinds of agarwood. Phytochemistry 23(9): 2068-2069. 